\title{
INTER-LABORATORY COMPARISON OF ACCREDITED LABORATORIES IN TERMS OF BENCHMARKING IN SLOVAKIA
}

The overall implementation of active benchmarking - the transfer and implementation of good practice in a closed circle in inter-laboratory comparisons its one of his components. To ensure that mission it's been created inter-laboratory comparisons model for benchmarking and as a support web system. The system is open to different types of quality indicators and its $c$ showing basics compliance with accreditation requirements.

\section{Introduction - Outline of the Term Benchmarking}

Benchmarking is a concept that is as old as the Olympics in ancient Greece. Athletes recognised that performance could be continuously enhanced through comparison with others.

Benchmarking is not a standardized method and therefore, in practice, there are a number of definitions. The following two are probably the most widely accepted. The American Productivity and Quality Centre (APQC) [9] which currently represents the leading world benchmarking institution and initiates benchmarking projects long-term [14], defines benchmarking as the process of identifying, learning from, and adopting outstanding practices and processes from any organization, anywhere in the world in order to improve performance [1].

According to the official dictionary of the American Society for Quality (ASQ) [10] benchmarking is a technique whereby a company measures its performance against that of the world's best in class, determines how such companies achieved their level of performance and uses this information to improve its own performance[5].

The Slovak literature [22] states that benchmarking is a continuous and systematic process of comparison and measurement of any products, process or methods in any given organisation that have been deemed suitable for measurement in the attempt to define the goals and to improve the performance of the organization.

\section{Civil Engineering Testing in the Slovak Republic}

One of the instruments in regulating the market diversity of testing norms in civil engineering as well as the standardization of civil engineering testing at a professional level, is a process of accreditation whereby testing laboratories must conform to the system and technical requirements of the norm STN EN ISO / IEC 17025 [24]. This norm creates a platform for comparing professional competence and stipulates the conditions for ensuring quality measurements and conditions for assuring quality of measurements.

The current construction environment is characterized by:

- high public demand for quality works;

- fast pace of construction; new entrants in the field of linear works construction;

- budget tensions;

- decline in skilled workers in relation to requirements,

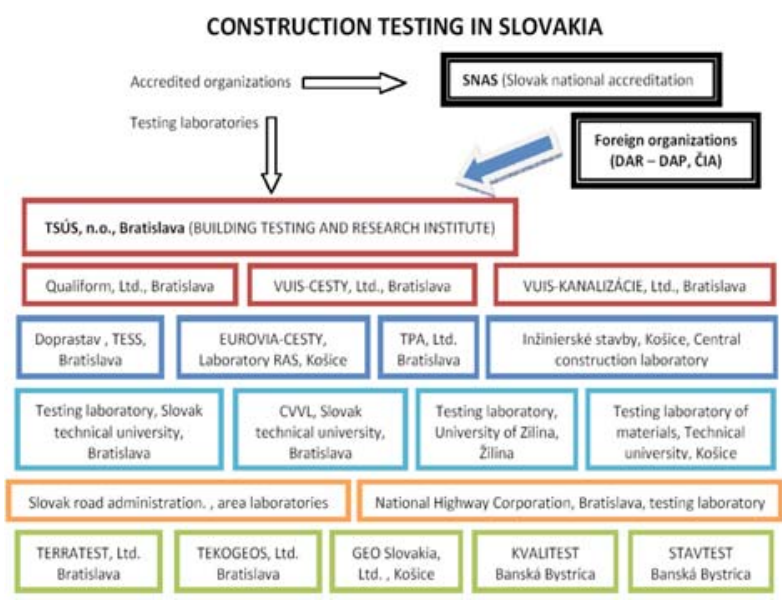

Fig. 1 Schematic representation of Civil Engineering testing in the Slovak Republic

\footnotetext{
* Maria Trojanova, Katarina Zgutova, Lubomir Pepucha, Martin Pitonak

Department of Technology and Management, Faculty of Civil Engineering, University of Zilina,

E-mail: maria.trojanova@fstav.uniza.sk
} 
- the introduction of new technologies and modern methods of testing building materials and construction elements.

Therefore, in the context of active benchmarking, inter-laboratory comparisons are a significant component of the transmission and implementation of good practice in civil engineering. As a result, and in order to achieve high quality inter-laboratory comparisons, a model of civil engineering testing has been created - Fig. 1 .

\section{Benchmarking Classification}

Based on the findings of research, the following benchmarking classification was determined [20]:

- competitive benchmarking - where the subject of interest is a particular product or performance of direct competitors on the market;

- functional benchmarking - where one or several functions of certain organizations are compared;

- generic benchmarking - where the centre of attention is the comparison and measurement of the specific organization's process. This applies to any appropriate organization with a similar process, although it may well not be a direct competitor.

Depending on where the benchmarking is performed, it is classified as:

- Internal - performed within one organization between units which have the same or similar processes and functions;

- External - where the partner for comparison and measurement is a different organization.

\section{The Practical Importance of Benchmarking}

Benchmarking in general:

- helps to better understand requirements of customers and other stakeholders

- allows managers to obtain information that would otherwise come to light accidentally, or would remain unknown - also helps to dispel unwarranted optimism

- is the way towards the discovery of objective indicators for measuring own performance and productivity in order to accurately identify own strengths and weaknesses,

- is one of the most effective ways of gathering suggestions for improvement.

Benchmarking is not strictly a closed process or a method with clearly defined rules and procedures. The number of stages or steps is very diverse and varies in different companies and organizations from 4 (representing the PDCA cycle - Fig. 2) up to 20 steps. The starting cycle for the application of benchmarking onto accredited laboratories is a four step cycle, with customer involvement as per Fig. 3 .

For all professionals in the field of quality management, it is important to note that the draft of the new ISO 9004 incorporates the article 8.3.5 recommendation that benchmarking methods

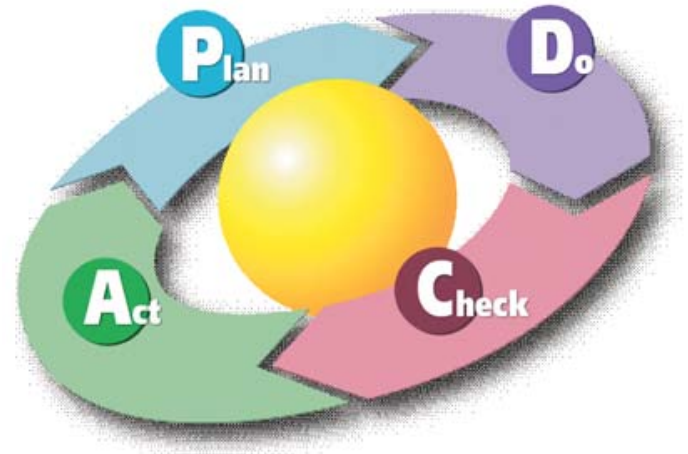

Fig. 2 Benchmarking four-step PDCA cycle [33]

should adhere to clearly defined rules and procedures [14]. It may therefore be expected to supplement the ISO 17025 which is currently fully compatible with the standards of the 9000 class.

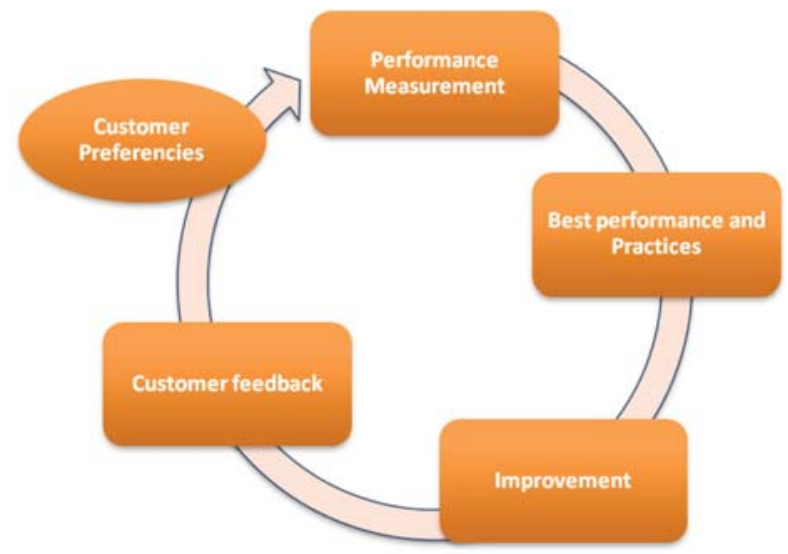

Fig. 3 Customer involvement in benchmarking process

Also, it is likely that benchmarking will become a component of accredited laboratories, thus becoming not only a comparison in the area of test results, which are subject of inter-laboratory comparisons, but also in the system section, which is also supported in the ISO/IEC 17025: 1999 point 5.9.

The laboratory shall have quality control systems to monitor the validity of the tests and calibrations undertaken. The data collected has to be recorded in such a way as to identify trends and, where feasible, to use statistical methods to assess results. This monitoring has to be planned and controlled, and may include, but not be restricted to, the following: participation in inter-laboratory comparisons or competence testing projects.

As a result of these developments, a benchmarking tool is proposed: - a web portal which is to be an open system for different types of quality indicators. The only valid outcome for any process of benchmarking is to identify areas for self improvement. It is the implementation of projects of improvement which gives benchmarking a meaning. 


\section{Benchmarking in testing laboratories}

There are three basic prerequisites for customer oriented benchmarking in testing laboratories [6]:

1. Leadership. Customer oriented benchmarking, in the most cases requires a complete reorientation from thinking in the terms of maintenance resources, production and activities, to thinking in terms of providing a product and service that are important for the customer; whilst, at the same time, thinking in terms of efficiency and performance related to products and services. Such reorientation requires strong support from the management. Without leadership, moving towards customeroriented benchmarking will not be successful.

Another aspect of good leadership is to bind the organization to the benchmarking. Time, effort, labour resources and attention to the data required from each laboratory should not be underestimated. It is necessary to use the same performance measurements for all the benchmarking partners; however, it is very likely that the data will not be uniform at the start Data should be collected in accordance with a specific plan. The practices at all levels of any given laboratory must be documented and shared with the benchmarking partners; especially if these have a different organisational structure. It is also necessary to make a commitment to implementing the ideas emerging from benchmarking and ensure that goals are actually achieved. It should also be borne in mind that performance measurements and new practices will mean re-deployment of resources within a laboratory

1. Culture. The culture of the work environment must support the idea of continuous quality monitoring and improvement. Customer oriented benchmarking requires a culture which is not always satisfied with the status quo and does consider it set in stone. Prior to starting benchmarking, it is helpful to view change and comparison with others as a way of improving the product and service for the customer. Management should monitor and analyse successes, reward improvements and genuine effort and be able to rapidly spot failures.

2. Common indicators. Participants in customer orientated benchmarking must agree with the measurements to be used. It is much easier to find a consensus about measurements within a laboratory than to accept external standards.

\section{Benchmarking indicators and their units}

Benchmarking indicator indicates to what extent the laboratory achieves the performance of competition

$$
U_{b}=\frac{P_{v}}{P_{v k}} \cdot 100
$$

where:

$U_{b}$ - benchmarking indicator [\%]

$P_{v}$ - characteristic parameter of performance of own organisation $P_{v k}$ - identical parameter of performance of the competition

The increasing value of this indicator and its permanently getting closer to $100 \%$ is obviously a positive trend [2].
This part is one of the key outcomes and suggests a catalogue of measurable indicators suitable for benchmarking of accredited laboratories - orientated to the customer - purchaser together with units. These indicators are those that are directly or indirectly relevant to the customer, however, there are many other measurements that are already recognized or are still to be identified.

The measurements are divided according to elements - items required for accreditation and then by attributes, where are associated measurements and their units and the note. The catalogue should include items such as the following:

1. Sampling

2. Validation of methods

3. Data control

4. Assurance of quality tests results - this is the only indicator that is measured within the scope of inter-laboratory comparisons

5. Complaints

6. Personnel

7. Handling the testing items and other.

Indicators of selected items are identified by:

- professional assessment

- brainstorming

- studying professional literature

- cooperation with accredited laboratories staff

It is an open system where items are associated with attributes, methods of measuring and units, as for example:

Quality indicators example

Table 1

\begin{tabular}{|l|l|l|l|}
\hline Attribute & Measuring & Units & Note \\
\hline $\begin{array}{l}\text { Homogen } \\
\text { eity of the } \\
\text { sample }\end{array}$ & $\begin{array}{l}\text { Standard } \\
\text { deviation }\end{array}$ & $\begin{array}{l}\text { Quadrate } \\
\text { of } \\
\text { evaluated } \\
\text { parameter }\end{array}$ & $\begin{array}{l}\text { Procedure which is carried } \\
\text { out by the laboratory and its } \\
\text { instruments }\end{array}$ \\
\hline $\begin{array}{l}\text { Discordan } \\
\text { t sample }\end{array}$ & $\begin{array}{l}\text { Average } \\
\text { number of non- } \\
\text { homogeneous } \\
\text { samples }\end{array}$ & Number & $\begin{array}{l}\text { Procedure which is carried } \\
\text { out by the laboratory and its } \\
\text { instruments }\end{array}$ \\
\hline
\end{tabular}

Benchmarking costs:

- Costs of meetings - include the costs of overheads. This includes travel, accommodation, per diem allowance and other costs,

- Costs of time - benchmarking team participants invest their time to review the problems, to find suitable and willing partners, time for mutual visits, not to mention the time for analysis and implementation. All this means that participants are absent from their work, and must be replaced by auxiliary workers,

- Costs of benchmarking database - an organization that wishes to introduce benchmarking into the daily process must create and maintain a database of their benchmarking results, and the best results of participating organizations. 


\section{Web Portal as a Basic Benchmarking Tool}

Web portal for benchmarking emerged as a result of the practical need to make the execution of inter-laboratory measurements more efficient. The system for benchmarking of accredited laboratories is designed and intended for comparative purposes. Its applicability is therefore far broader. It can also be used for com parison in other sectors of construction and by other construction works operators.

\section{Starting Points for the Emergence of the Portal}

The starting point for designing the system was that it should be flexible and useful for comparing all types of laboratories at al levels, to be used not only within the Slovak area, but also in Europe. If need be, it can serve a single organization, such as the National Motorway Company - at the level of motorway construction, as a tool for selecting an accredited laboratory.

Due to the reasons listed, it is possible to expect a large range of different types of indicators, parameters and categories that require different entries. Therefore, the starting point in creating the system was the design of forms by an administrator, with the relevant number of columns and rows to record units, as desired. The representatives of laboratories have to enter basic information about the laboratory and, subsequently, parameters they have measured and the basic characteristics of the testing environment These characteristics can be edited by the administrator.

Benchmarking participants, after permission to register, have to fill in individual forms designed by the administrator.

Participation of laboratories in benchmarking process provides objective evidence about the reliability of the results [26] they produce, allows them to identify sources of potential errors and subsequently to improve the quality of their work. The motivation of individual entities is the need to compare the results of their own work with other laboratories (partners but also competitors).

Participation of laboratories in competence testing and comparative measurements is an important part of showing compliance with the accreditation requirements. It is one of the key criteria to fulfil the accreditation requirements of accredited laboratories [24]. For this reason, it is very important that laboratories, in their own interest, participate in such competence tests and comparative measurements.

Company Calibrium, Ltd., in conjunction with the Faculty of Civil Engineering at the University of Zilina, organizes the national competence tests and comparative measurements in the field of construction, in accordance with the valid Methodical Guidelines for Accreditation and the Slovak National Accreditation Service, and coordinates the national system of competence testing and comparative measurements aimed at:

- allow, within limits, the individual laboratories to prove compliance with the follow-up and measuring instruments via participation in the competence testing and comparative measurements,
- serve as an effective tool of the Slovak National Accreditation Service for ensuring the comparability of results of testing and calibration activities of laboratories.

\section{On-line application of benchmarking}

The basic assumptions the application should meet are:

- multi- platform, namely the independence of the system used by the testing laboratory or other organization,

- accessibility not only via LAN, but also over the Internet (accessible 24 hours a day).

Due to the reasons discussed, the most suitable solution for the customer driven benchmarking appears to be the use of the platform Client - Server, which allows complete separation of the application section from the user section, where the user enters the data and results into the user interface on his or her computer and these are evaluated, processed by a program located on the server.

The connection between the User - Client and Server must be encrypted by SSL protocol, in order to prevent leakage of information that the testing laboratory or other organization is not willing to disclose. In this way, the operating body guarantees the inviolability of the information provided by the testing laboratory for comparison. Implicitly, the table of results with information from testing laboratories will identify the laboratory only as a number, which will be changed regularly and different for each testing laboratory.

\section{Application environment}

Due to the diversity of operating systems, software facilities on user computers we applied the environment of web pages for communication of testing laboratories with the server. This ensures trouble free access into the application for all users - testing laboratories. Server hardware is located in an air-conditioned server room, under 24 hour surveillance by security service, camera system, and a system for ensuring constant connection of servers.

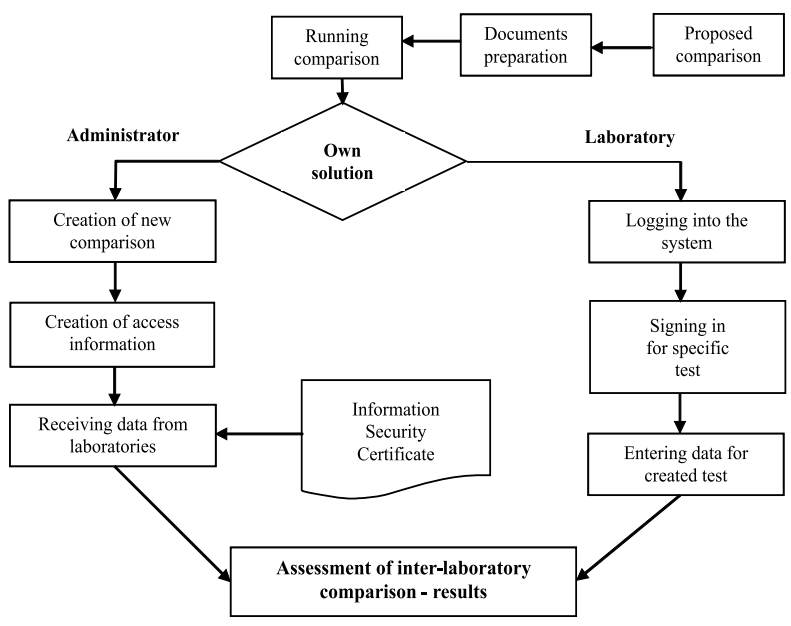

Fig.4 Scheme of on-line comparison process 


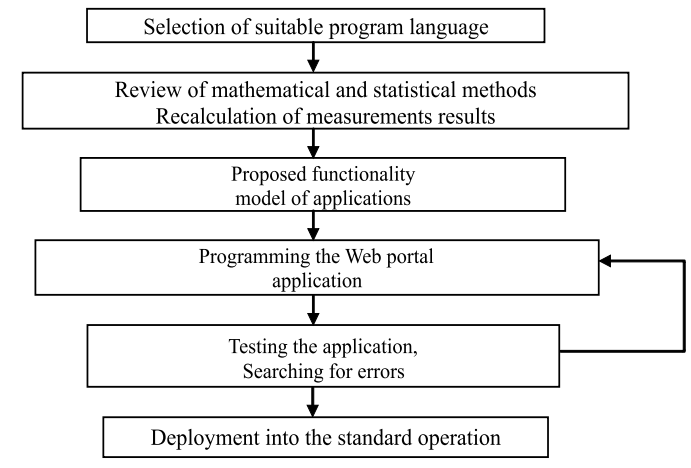

Fig. 5 Scheme of work on creation of web portal application

\section{Web portal user interface}

After studying mathematical methods for statistical comparisons of inter-laboratory tests, we started programming the application itself. The body of the application is divided into the following sections for clarity.

- Logging into the application, we resolved by an allocation of a unique code, which will be allocated to the particular laboratory by a generator program in order to avoid possible human error. Application users will authenticate themselves by the username and the assigned code. On the server we created a secure connection via HTTPS (encryption by generated, or Certification Authority verified, authoritative certificate). In terms of application users, the highest level of security will be ensured.

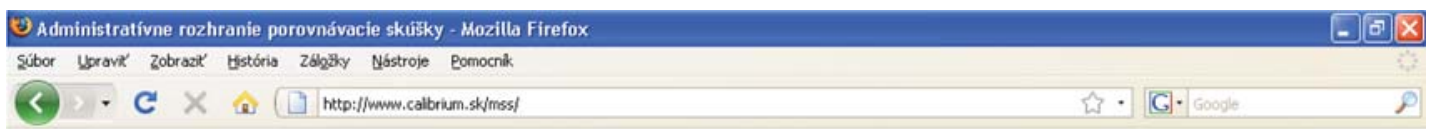

vitajte na administratívno rozhraní porovnávacích skúškok

\begin{tabular}{|l|l|}
\hline $\begin{array}{l}\text { Pritlosovacie meno: } \\
\text { Heslo: }\end{array}$ & \\
& Zadake prosim Vaše meno a heslo \\
& Prihlásit \\
\hline
\end{tabular}

Fig.6 Logging into the application

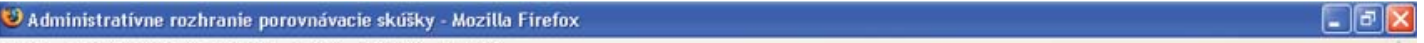

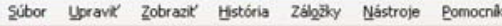

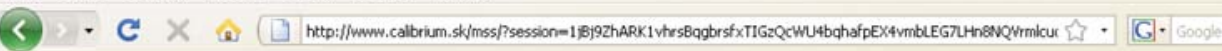

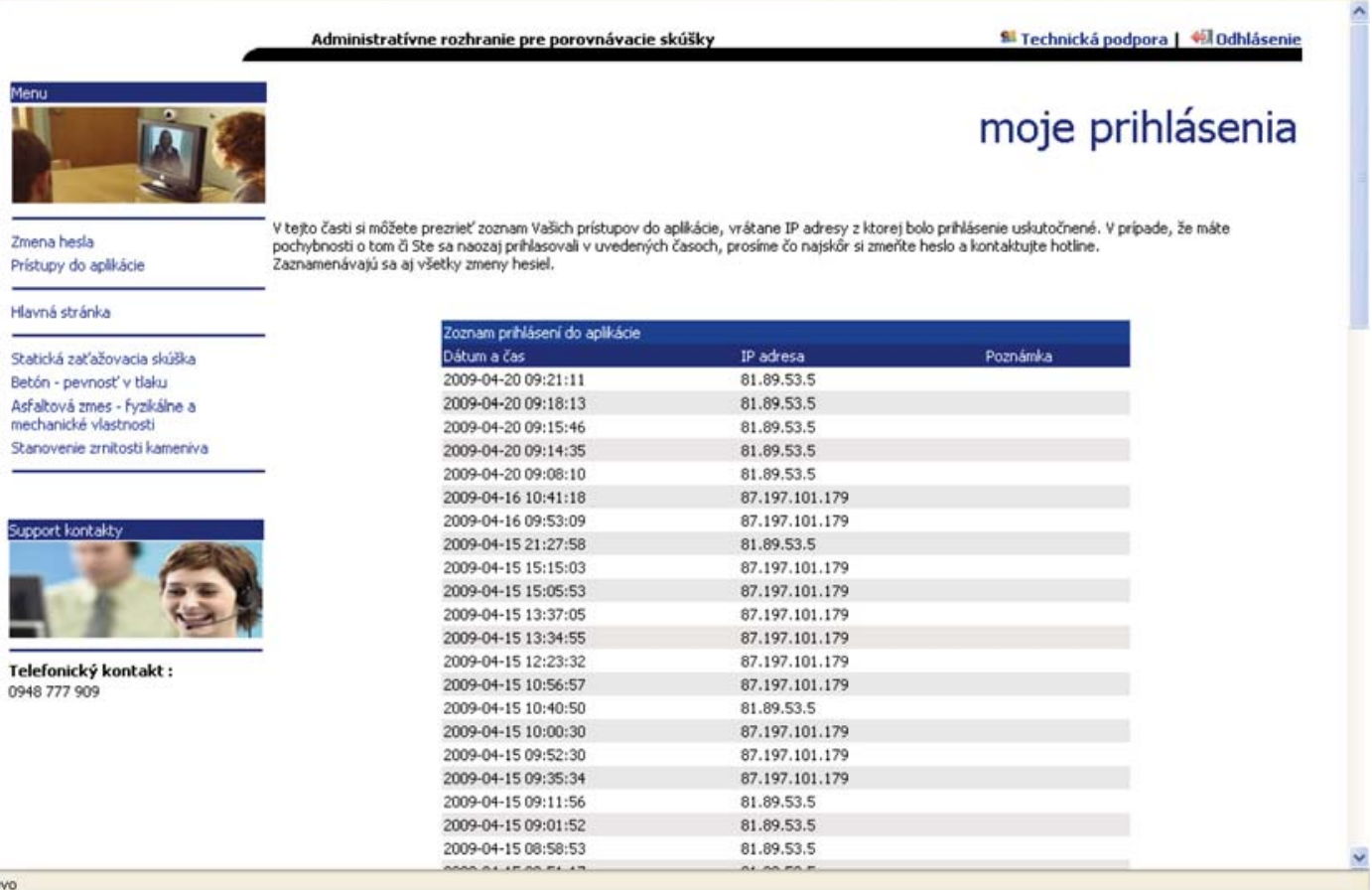

Fig. 7 Recording access to the application 


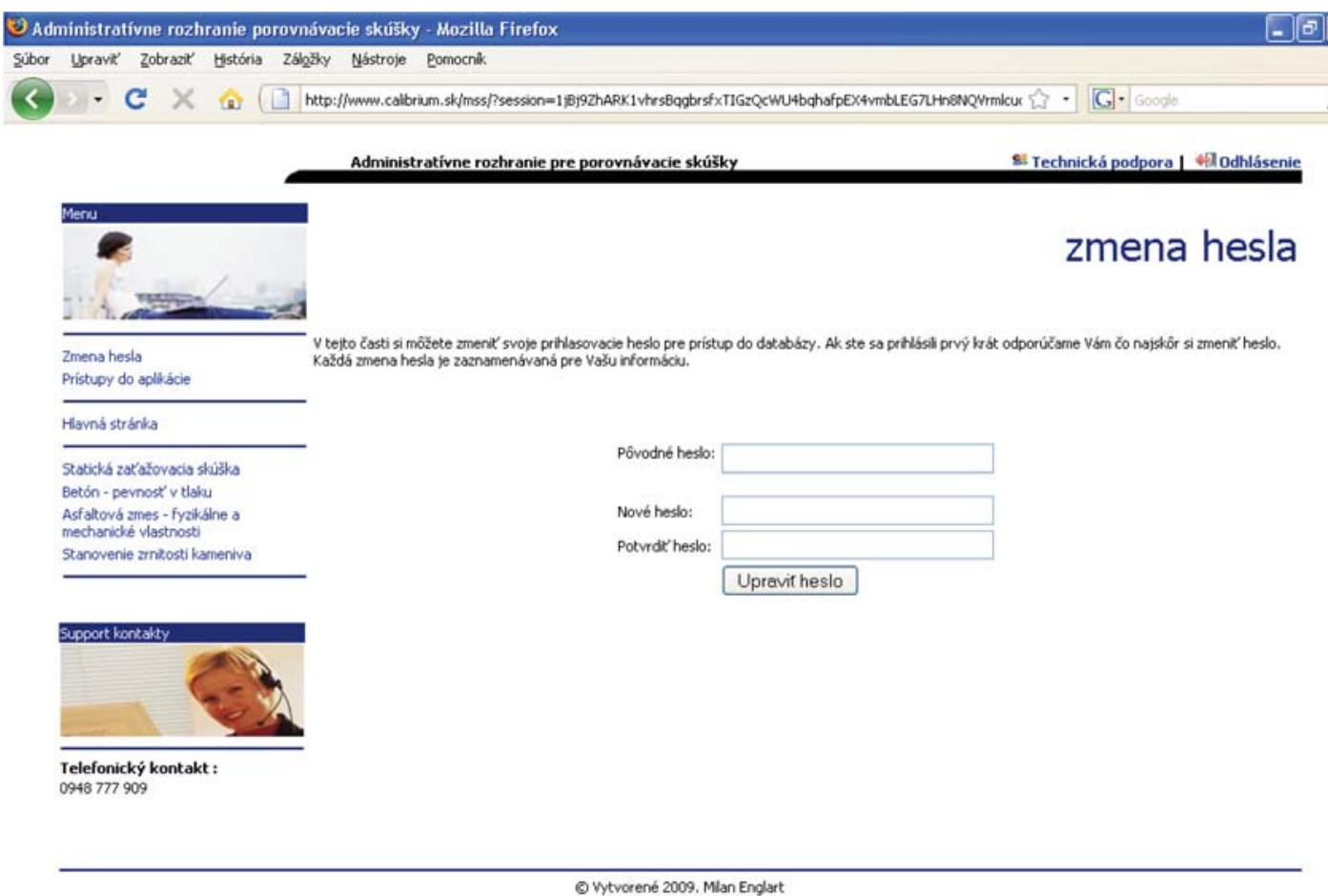

Fig. 8 Option to change the application access password

For authentication of users we incorporated to the application a system for recording the access into the application.

At the same time the database stores IP address from which the application was accessed, password changes and other important data facilitating the detection of potential misuse of access data. Each figure recorded in the database is Time Stamped, thus the time is precisely defined and can not be changed not even by the administrator.
Password change - following successful login, the user has the option to change the password. The minimum number of characters for the password, we selected six characters.

- Data entry - we chose a system where an application user selects, in the left hand menu, the test for which she or he wishes to enter the data, for example for the static load test. Following the click on the given item, the form will appear and the user can enter the values measured. In the future we anticipate more

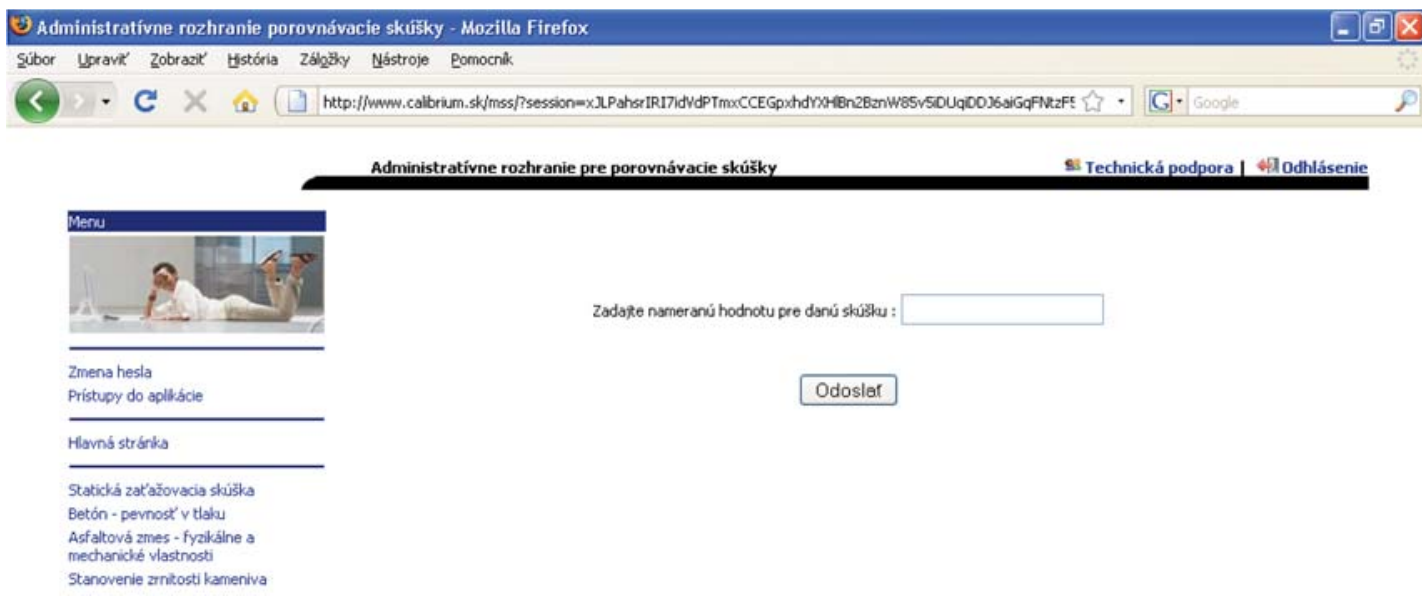

Fig. 9 Method of data entry into the application 
benefits in the automatic control of data entered, in order to prevent the entry of diametrically opposed data because of human error.

- Displaying the results - if the user enters his or her values for particular measurements and other participants in inter-laboratory comparison have done the same, the evaluation will be displayed. To protect the user data, each user views the results table reshuffled. So even if 2 users agree that they will provide the results table to each other, it will not be identical, the arrangement of laboratories will be different.

- Trial testing - we created a group for testing the web application. Each participant was assigned a unique code for the laboratory test. The user logged into the application under her/his name and password and entered the value measured, specifically for Concrete - compressive strength. Unfortunately, some participants were not familiar enough with the system and entered incorrect values, and therefore it was necessary to send them the information about re-entering the results into applications. This delay meant that the outcome of inter-laboratory comparison was not evaluated in the expected time frame. However, we see the possibility of adjustments in the future.

- System Adjustments - during the simulation of the inter-laboratory comparison minor errors appeared and are currently being remedied; this mainly concerns:

- control of input data entry

- allowing the continuous monitoring of the results of comparison

- possibility to export the results to PDF, CSV or other.

\section{Acknowledgement:}

This contribution is the result of the project implementation: "Centre of Excellence in Transport Engineering" (ITMS: 26220120027) supported by the Research \& Development Operational Programme funded by the ERDF.

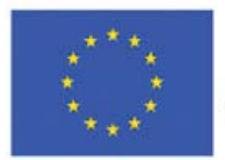

Európska únia
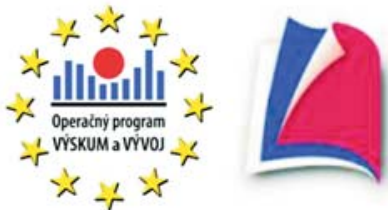

Agentúra

Ministerstva školstva, vedy, výskumu a športu SR pre štrukturálne fondy EÚ

\section{References}

[1] CAMP, R. C.: Business Process Benchmarking. ASQS Quality Press. Milwaukee, 1995, p. 464, ISBN 0-87389-296-8.

[2] DOUGLAS, C., MONTGOMERY: Introduction to Statistical Quality Control. Third edition, ISBN 9780471303534, Publisher John Wiley \& Sons Inc.

[3] Draft FDIS ISO 9004-N6 (17/04/2009). Geneva ISO 2009.

[4] ENGLART, M: Medzilaboratorne porovnavania v ponimani benchmarkingu riadeneho zakaznikom [Inter-laboratory comparisons in terms of customer-driven benchmarking]. Diploma Work, KTMS, SvF, ZU, 2009.

[5] Glossary of terms Related to Quality Management. In: www.asq.org, 10.4.2007.

[6] HARRINGTON, H. J., HARRINGTON, J., S.: High Performance Benchmarking, 20 Steps to Success. McGraw-Hill : New York, NY, 1996.

[7] HOLlOWAY, J., FRANCIS, G., HINTON, M., HAYLE D.: Best Practice Benchmarking. TQM 4/1998

[8] http://en.wikipedia.org/wiki/PDCA, 18.11.2009.

[9] http://www.apqc.org/portal/apqc/site, 17.11.2009.

[10] http://www.asq.org., 17.11.2009

[11] http://ww1.efqm.org/en, 17.11.2009.

[12] MIKOLAJ, J., SCHLOSSER, F., VALUCH, M., ZGUTOVA K.: Zavedenie systemu kvality v oblasti vystavby, udrzby a oprav ciest [Introduction of quality management system in the field of road construction and maintenance]. Report No.6-3/83/SvF/03, University of Zilina.

[13] MSA 0113-98 Skusky sposobilosti. Cast I. Zasady vyberu, organizovania a hodnotenia skusok sposobilosti SNA [Competence Tests. Part I. Principles of selection, organization and evaluation of competence tests SNA]. SNAS, p. 34, Bratislava April 1998.

[14] NENADAL, J.: Jak zacit s Benchmarkingem? [How to start with benchmarking?]. Part 1. In: Quality 2/2009, ISSN 1335-9231, pp. 22-29.

[15] NENADAL, J.: Jak zacit s Benchmarkingem? [How to start with benchmarking?] Cast 2. In: Quality 3/2009, ISSN 1335-9231, pp. 17-23.

[16] NENADAL, J.: Mereni v systemech managementu jakosti [Measuring in quality management systems]. $2^{\text {nd }}$ ed. Management Press: Praha 2004.

[17] NENADAL, J., NOSKIEVICOVA, D., PETRIKOVA, R., PLURA, J., TOSENOVSKY, J., VYKZDYL, D.: Jak zvysit vykonnost organizaci [How to increase organization's performance]. Ostrava : Dum techniky, 2008, p. 239, ISBN 978-80-7261-164-5. 
[18] OAKLAND, J., S.: Oakland on Quality Management. Amsterdam: Elsevier Butterworth Heinemann. 2004, p. 476, ISBN 0-75065741-3.

[19] PITONAK, M.: Vyuzitie vybratych metod systemov manazerstva kvality pri udrzbe a opravach cestnych komunikacii [The use of selected methods of quality management systems at maintenance and repairs of roads]. Thesis, KTMS, Faculty of Civil Engineering, University of Zilina, 2008.

[20] PITONAK, M., ZGUTOVA, K.: Nastroj pre benchmarking spravcov cestnych komunikacii [A Tool for benchmarking of road operators]. In: Proceedings from the $17^{\text {th }}$ Intern. Conference: Quality-2008, ISBN 978-80-02-02032-5, Ostrava, 2008, pp. C28-C33.

[21] SAMUEL, K. M. H.: TQM, an Integrated Approach. Implementing Total Quality through Japanese 5-S and ISO 9000, Published in 1995, Kogan Page : London, 0749415614, p. 292.

[22] STARSI, B.: Vyznam medzilaboratornych porovnavajucich skusok pri posudzovani sposobilosti skusobnych laboratorii [The meaning of inter-laboratory comparative tests at assessing the competence of testing laboratories] In: Proc. from $9^{\text {th }}$ Intern. Conference: Road Conference Q-2007, ISBN 978-80-969681-0-7, Zilina, 2007, pp. 177-182.

[23] STN EN ISO 9004:2001: Quality Management Systems. Guide for efficiency,

[24] STN EN ISO/IEC 17025:2005: General Requirements for the Competence of Testing and Calibration Laboratories. SUTN Bratislava, 10/2005, p.37.

[25] SPACKA, M.: Co je a co neni benchmarking [What is and what isn't benchmarking]. In: Modern Management, 3/2005. Praha: Economia, 2005. ISSN 1213-7693.

[26] STEFANIK, A., MICIETA, B.: Benchmarking - indexove porovnavanie [Benchmarking-index comparison]. In: Modern approaches towards firms management. Trnava, 2002, STU, pp. 245-249, ISBN 80-227-1706-1.

[27] TEREK, M., HRNCIAROVA, L.: Statisticke riadenie kvality [Statistical quality management]. Bratislava : IURA EDITION, 2004.

[28] VALUCH, M., TROJANOVA, M., CURAJ, M: Application of Process Approach in Public Procurement of Highway Projects. In: Civil and Environmental Engineering, 1/2008, ISSN 0336-5835, pp. 2-4.

[29] VLCEK, R.: Management hodnotovych inovaci [Management of value innovations]. Praha: Management Press, 2008, p. 239, ISBN 978-80-7261-164-5.

[30] WAN, E., WAN, J., MOKHTAR, A., NOOREHA, H.: Benchmarking institutions of higher education. In: Total Quality Management, 7/2000, Vol. 11, Issue 4/5/6, p. S798, ISSN: 09544127.

[31] WEBER, R.: The Benefits of Benchmarking. In: Trailer/Body Builders, 7/2005, Vol. 46, Issue 9, pp. 82-83, ISSN: 0041-0772.

[32] ZGUTOVA, K., PITONAK, M.: Benchmarking $v$ cestnom hospodarstve [Benchmarking in road economy]. In: Proc. from International Conference - 2006 Road Conference, Rajecke Teplice, 2006.

[33] W.Edward Deming (1900-1993). 